\section{Influences on women's choice of the levonorgestrel-releasing intrauterine system}

We write to report a recent European survey of factors that motivate women to use or reject the levonorgestrel-releasing intrauterine system (LNG-IUS). The survey comprised focus group sessions to identify barriers that prevent women using the LNG-IUS and individual interviews with current users to identify their reasons for having chosen the LNG-IUS.

A total of 297 women from France, Germany, Italy, Poland, Russia, Spain and Turkey were included in Part One of the survey. Two-hour discussion sessions based on a prepared list of topics identifying barriers to using the LNG-IUS were held with groups of six to eight randomly selected eligible volunteers aged 17-45 years ( $\geq 18$ years in Poland). Participants were currently using a form of contraception other than the LNGIUS and were categorised as (1) nulliparous, but possibly desiring children in the future; (2) parous, planning more children in the future or uncertain; or (3) parous, with no plans for further children. Women who were not prepared to consider using hormonal contraception under any circumstances were excluded. Part Two of the survey comprised individual interviews with 72 current users of the LNG-IUS in France, Germany, Italy, Poland and Spain, using prepared questions to identify their opinions of, and reasons for choosing, this form of contraception Participants were offered a small monetary incentive, in line with local guidelines.

Both the focus group sessions and the interviews were open-ended and explored participants' current and past methods of contraception; reasons for their choices; sources of information, attitudes and knowledge regarding the LNG-IUS; and reasons for choosing or rejecting the LNG-IUS. Verbatim transcripts from the group sessions and interviews were analysed using accepted methodology 1 and studied to identify key words and ideas, which were subsequently grouped into a series of themes.

In Part One of the survey, two focus group sessions in each country were conducted for each participant category. There were few differences between countries in terms of the most commonly used forms of contraception (oral contraceptives and condoms). The exception to this was Turkey, where the copper IUD predominates. Greater differences were seen between participant categories, reflecting the individual needs of each group. For example, ability to become pregnant soon after the LNGIUS removal was unimportant to those who had completed their families.

Factors influencing the potential use of the LNG-IUS that emerged from the focus group discussions are shown in Table 1. The prime concern of participants from Italy, Poland, Russia, Spain and Turkey was the cessation of menstruation, which is known to occur in approximately $20 \%$ of LNG-IUS users. These concerns were often found to be based on misinformation (from website chat rooms or personal communications) rather than on advice from doctors

In Part Two of the survey, 72 current LNG-
IUS users participated in 1-hour interviews. Reasons for having switched to the LNG-IUS included reduced risk of unintended pregnancy, family planning after the birth of a child, tolerability and compliance issues with ora contraceptive pills, or inconvenience of barrier methods. All women had sought advice from their gynaecologist or general practitioner before deciding to use the LNG-IUS but had consulted more easily accessible (although not necessarily accurate) sources of information first, such as friends or the Internet.

The chief reasons for having chosen the LNG-IUS were convenience associated with its long-term effect, and low hormone content. These were also identified as desirable attributes of the LNG-IUS by the non-users in the focus groups. Other reasons included elimination of the need for regular contraception, and for women with or planning to have more children compatibility with breastfeeding and resumption of fertility immediately on removal. Anothe associated benefit was lighter, shorter, less painful periods. The main reported disadvantage of the LNG-IUS was pain on insertion.

This survey investigated the reasons underlying women's choice of contraception, specifically in relation to the LNG-IUS Inaccurate or misleading information from anecdotal sources is relied upon by many women whose concerns could be addressed with proactive counselling by their physicians. These findings are consistent with those of Asker et al. who analysed the concerns of women who had never used an IUD. ${ }^{2}$ Although the two populations in the present investigation were surveyed by different methods, their perception of the attributes of the LNG-IUS were broadly similar, with long duration of effect and low hormone content viewed as important. A recen US-based Phase III study of the LNG-IUS in 509 women aged 18-45 years found that precounselling about possible side effects was associated with continued long-term use of the LNG-IUS. ${ }^{3}$ The present survey highlights the importance of soliciting the views of women and the factors that influence their decisions on contraceptive choice.

Malgorzata Binkowska, $\mathrm{MD}, \mathrm{PhD}$ Specialist in Gynaecology, Midwifery and Endocrinology, Department of Obstetrics and Gynaecology, The Medical Centre of Postgraduate Education, Warsaw, Poland. E-mail:mabi@onet.pl

Thierry Harvey, MD, FRCOG

Chef de service, Maternité, Hôpital des Diaconesses, Paris, France

tatements on funding and competing interests Both authors have acted as paid consultants for Bayer Schering Pharma.

\section{References \\ Rabiee F. Focus-group interview and data analysis. Proc Nutr Soc 2004; 63:655-660. \\ Asker C, Stokes-Lampard H, Beavan J, Wilson S. What is it about intrauterine What is it about intrauterine devices that women find qualitative study. J Fam Plann Reprod Health Care $2006 ; 32: 89-94$ 3 Jensen JT, Nelson AL, Costales AC. Subject and intrauterine system. Contraception 2008; 77 : 22-29.}

Table 1 Advantages and disadvantages of the levonorgestrel-releasing intrauterine (LNG-IUS) system identified by LNGIUS non-user focus group participants

\begin{tabular}{ll}
\hline Perceived advantages of the LNG-IUS & Perceived disadvantages of the LNG-IUS \\
\hline As effective as sterilisation & Lack of menstruation \\
No decrease in efficacy during illness & Several possible side effects \\
No risk of forgetting & Foreign body \\
Lasts for 5 years & Possible pain with insertion and removal \\
Low hormonal dose & Possible damage with insertion and removal \\
Pregnancy possible immediately after removal & High cost \\
Analgesia may be used during placement & No protection against sexually transmitted infections \\
Targeted action & \\
Can be used when breastfeeding & \\
Not felt during use & \\
\hline
\end{tabular}

\section{IUD fitters and training in resuscitation}

We are two clinical nurse specialists with experience of running a nurse-led intrauterine device (IUD) clinic since 2000 and with roughly 1000 insertions between us. None of our patients has ever needed atropine, despite us coping with some vasovagal attacks in the manner described by Diana Mansour. ${ }^{1}$ We feel that it is good counselling, friendliness and the almost universal use of local anaesthetic that helps to prevent the need for intervention of this sort. Ensuring that the woman has eaten before the procedure is also part of the preventative measures.

Please can we be given some real evidence as to why the Royal College of Nursing (RCN) and the Faculty of Sexual and Reproductive Healthcare (FSRH) persist in pursuing this policy of insisting a doctor is present? It is interesting from Shelley Mehigan that both organisations seem to think they are taking the lead from the other.

Perhaps the question that needs to be looked at is the one of the use of atropine in this setting. Anecdotally it seems that clinicians working in this field have not needed to use atropine. We feel that this may be the idea to be discussed and clarification would be most welcome for clinicians and their service.

We work in a time of 'evidence-based decisions' and yet from all the correspondence that this has generated there is clearly none to justify this situation.

Maggie Gormley, RGN, AO8

Nurse Specialist, The Margaret Pyke Centre, London, UK.

E-mail:maggie.gormley1@googlemail.com

Ann Eady, RGN, AO8

Nurse Specialist, The Margaret Pyke Centre,

London, $U K$.

E-mail: ann_eady@hotmail.com

Reference

Mansour D. Nurse training and the need for IUD fitters o have expertise in resuscitation [Letter]. J Fam Plann Reprod Health Care 2010; 36: 180

IUD nurse fitters and resuscitation I read with interest Shelley Mehigan's reply to Diana Mansour's letter in the July edition of the Faculty journal.1,2 This is certainly a major concern and like many areas we too have felt the need to suspend nurse intrauterine device (IUD) fittings until further guidance is available.

Obviously this has huge implications for patient access and loss of clinical skills for the nurses involved. I am hoping that by now either the Faculty or the Royal College of Nursing $(\mathrm{RCN})$ may be able to offer us further guidance? Just as Shelley Mehigan clearly states in her reply, I too am astonished that this sudden requirement should be justified for nurses alone. Surely this has implications for medical practitioners too?

I would be really grateful for any advice as to when guidance may be available, so that we can project when we may be able to resume normal services

Kate Davies. $\mathrm{RCN}$

Locality Team Manager, Sexual Health Department, Bridge House, Sleaford, UK.

E-mail:Kate.Davies@lpct.nhs.uk

Mehigan S. Nurse training and the need for IUD fitters to have expertise in resuscitation [Reply to Letter]. $J$ Fam Plann Reprod Health Care 2010; 36: 180 . Mansour D. Nurse training and the need for UDD fitters to have expertise in resuscitation [Letter]. J Fam Pltan Reprod Health Care 2010; 36: 180. 